KY FACE \#97KY082 Date: 31 October 1997

\title{
Farmer Crushed When Run Over by Tractor and Disc
}

\section{SUMMARY}

A 75-year-old farmer was killed when he was run over by a tractor and disc attachment. The farmer attempted to start the engine on a tractor while he stood on the ground beside it, a practice which was not unusual for him. The transmission had been left in gear and when the ignition was started the tractor lurched forward knocking the victim to the ground. The tractor continued to move forward, running over the victim. His wife went to search for him when she realized he had been gone from the house for quite some time. She found him in the field pinned under the disc that was attached to the tractor. She returned to the house to call 911. Rescue personnel were dispatched at 4:16 pm and arrived on the scene within minutes. The county coroner was summoned to the scene and pronounced the victim dead. In order to prevent similar incidents from occurring, FACE investigators recommend:

- Never attempt to start a tractor unless seated in the driver's seat.

\section{INVESTIGATION}

On August 13, 1997, FACE was informed that a 75-year-old farmer had been killed in a tractor runover on July 2, 1997. An investigation was initiated. The coroner was interviewed via phone and a copy of the coroner's report was obtained. Access to the site was denied.

The victim was a retired dentist but he had also been involved in farming most of his life. After retirement, he continued to work on the berry farm that he and his wife owned. They hired help during the season as needed.

\section{INVESTIGATION}

On the day of the incident, the weather was warm and pleasant. At about $2 \mathrm{pm}$ the victim and his wife were in the house when they heard a car pull into the parking area. They assumed it was a customer to purchase or pick berries. As the farmer put on his shoes, his wife went outside to check. The car did not stay and the wife walked on down to the edge of the road to get the mail. When she returned to the house, she found that her husband had left. At about 4 pm, her husband had not come back to the house so she went out to the fields behind their home to look for him. She found her husband pinned under the disc that was attached to the tractor. There were no witnesses to the fatal incident. Apparently the farmer was in the field and attempted to start the tractor by standing beside it. An employee of the farm, who was not present at the time of the incident, stated that the victim often started the tractor by standing beside it rather than being seated in the driver's seat. The transmission had been left in gear and when the ignition was turned, the tractor lurched forward and knocked the victim to the ground. The tractor continued moving forward, running over the victim and crushing him under the disc. Upon finding her husband, she ran back to the house and called 911. Rescue personnel were dispatched to the scene at 4:16 pm. They arrived on the scene within minutes, but the 
victim showed no vital signs. The coroner was summoned at 4:39 pm and arrived at 4:55 pm. He pronounced the victim dead at the scene.

\section{CAUSE OF DEATH}

On the coroner's report, the cause of death is listed as massive head trauma due to farm tractor running over the decedent. An autopsy was not done.

\section{RECOMMENDATIONS/DISCUSSION}

\section{Recommendation \#1: Never attempt to start a tractor unless seated in the driver's seat.}

Discussion: Starting a tractor when in a position other than sitting in the driver's seat puts the operator at risk of serious injury. In this case, the victim never mounted the tractor before starting the engine and apparently did not realize that the tractor was in gear. Tractor operators need to be aware of this hazard and only start the ignition when in the driver's seat. Newer tractors require that the gearshift must be in the neutral position to start the engine, minimizing the risk that the tractor will suddenly jump forward. However, even with this feature, the safest position is for the operator to be seated.

click here to go back to the Kentucky FACE reports

click here to go back to the NIOSH FACE Web 